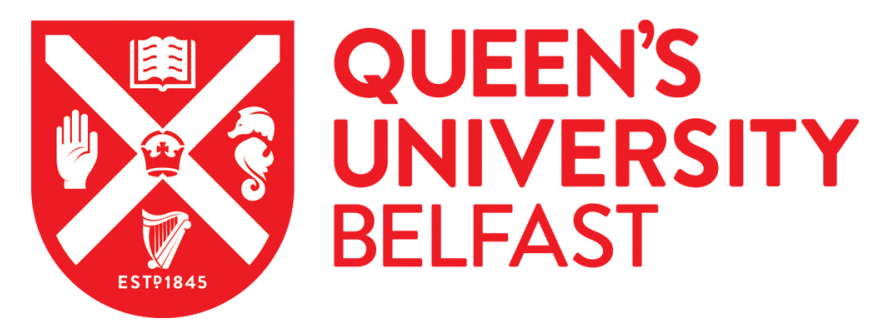

\title{
Urban/rural variation in the influence of widowhood on mortality risk: a cohort study of almost 300,000 couples
}

Wright, D. M., Rosato, M., \& O'Reilly, D. (2015). Urban/rural variation in the influence of widowhood on mortality risk: a cohort study of almost 300,000 couples. Health and Place, 34, 67-73.

https://doi.org/10.1016/j.healthplace.2015.04.003

Published in:

Health and Place

Document Version:

Peer reviewed version

Queen's University Belfast - Research Portal:

Link to publication record in Queen's University Belfast Research Portal

\section{Publisher rights \\ (C) 2015 Elsevier}

This is an open access article published under a Creative Commons Attribution-NonCommercial-NoDerivs License (https://creativecommons.org/licenses/by-nc-nd/4.0/), which permits distribution and reproduction for non-commercial purposes, provided the author and source are cited.

\section{General rights}

Copyright for the publications made accessible via the Queen's University Belfast Research Portal is retained by the author(s) and / or other copyright owners and it is a condition of accessing these publications that users recognise and abide by the legal requirements associated with these rights.

Take down policy

The Research Portal is Queen's institutional repository that provides access to Queen's research output. Every effort has been made to ensure that content in the Research Portal does not infringe any person's rights, or applicable UK laws. If you discover content in the Research Portal that you believe breaches copyright or violates any law, please contact openaccess@qub.ac.uk. 
1 Urban/rural variation in the influence of widowhood on mortality risk: a

2 cohort study of almost 300,000 couples

3

4

5

6 * Corresponding Author: Centre for Public Health, Institute of Clinical Sciences, Block B,

7 Queen's University Belfast, Royal Victoria Hospital, Grosvenor Road, Belfast, BT12 6BA

$8 \quad U K$.

9 Tel: +442890632631.

10 Email: d.wright@qub.ac.uk

11

12 


\section{ABSTRACT}

Death of a spouse is associated with increased mortality risk for the surviving partner (the widowhood effect). We investigated whether the effect magnitude varied between urban, rural and intermediate areas, assembling death records (2001-2009) for a prospective cohort of 296,125 married couples in Northern Ireland. The effect was greatest during the first six months of widowhood in all areas and for both sexes. Subsequently, the effect was attenuated among men in rural and intermediate areas but persisted in urban areas (HRs and 95\% CIs: rural 1.09 $[0.99,1.21]$; urban $1.35[1.26,1.44])$. Among women the effect was attenuated in all areas (rural 1.06 [0.96, 1.17]; urban 1.09 [1.01, 1.17]). The impacts of spousal bereavement varied between urban and more rural areas, possibly due to variation in social support provided by the wider community. We identify men in urban areas as being in greatest need of such support and a possible target for health interventions.

Key words: widowhood, bereavement, mortality rates, urban/rural

\section{RESEARCH HIGHLIGHTS}

- Mortality risk increases with death of a spouse (the widowhood effect).

- The association between area of residence and the widowhood effect was assessed.

- A total of 296,125 married couples were included in the analysis.

- The widowhood effect was attenuated over time for both sexes in rural areas.

- Men in urban areas remained at increased mortality risk but women did not. 
Widowhood is a common major life transition among older people that has been associated with elevated risk of mortality in the surviving spouse (the widowhood effect) across many populations, providing strong evidence that changes in social ties affect health outcomes (Shor, Roelfs et al. 2012, Manzoli, Villari et al. 2007). Besides gender differences (men usually experience a greater increase in relative risk than women - Moon, Kondo et al. 2011) various socioeconomic and health related factors moderate the widowhood effect (Boyle, Feng et al. 2010, Shor, Roelfs et al. 2012, Pandey, Jha 2012) and the largest relative increases in mortality risk are found in groups with low pre-existing risks of mortality (e.g. those with good health and high socioeconomic status - Shah, Carey et al. 2012, Boyle, Feng et al. 2010). Mortality rates associated with a variety of causes are elevated by widowhood indicating that the effect is not limited to a single pathway (Elwert, Christakis 2008) and three main explanatory mechanisms have been proposed: emotional stress and grief, loss of emotional social support and loss of instrumental (task related) social support (Martikainen, Valkonen 1996).

The widowhood effect is greatest during the first six months of widowhood (Martikainen, Valkonen 1996, Boyle, Feng et al. 2010, Moon, Kondo et al. 2011, Manor, Eisenbach 2003, Lichtenstein, Gatz et al. 1998, Lusyne, Page et al. 2001), especially deaths related with accidents, violence, alcohol or unexpected respiratory or circulatory diseases (Martikainen, Valkonen 1996, Shah, Carey et al. 2012). A proportion of the excess deaths due to cardiac conditions in the early stages of bereavement may result from inadequate condition management immediately prior to bereavement (Shah, Carey et al. 2013), indicating that acute stress at this stage contributes to the widowhood effect (Vable, Subramanian et al. 2015). As time since bereavement increases the mortality differential between widows and non-widows tends to decrease for women in the first ten years but may increase subsequently, whereas men are likely to show a sustained or increased mortality differential (Shor, Roelfs et al. 2012, Berntsen, Kravdal 2012, Martikainen, Valkonen 1996). In summary, grief and acute stress appear to play a significant role in elevating mortality risk in the early stages of widowhood, replaced over time by more subtle effects due to withdrawal of spousal support in daily living, both emotional and instrumental (Elwert, Christakis 2006, Stroebe, Schut et al. 2007).

Estimates of the magnitude of the widowhood effect are heterogeneous among studies but there have been few attempts to identify modifiers other than individual socio-economic or health status (Moon, Kondo et al. 2011), so we investigated the influence of socio-geographic context 
(urban or rural residence) on the widowhood effect. Urban-rural gradients in risk have been observed for several health outcomes; e.g. all-cause mortality in England (Riva, Curtis et al. 2011), mental health status across multiple developed countries, and have been attributed variously to stress, pollution, over-concentrated housing or social isolation in urban areas (O'Reilly, O' Reilly et al. 2007, Peen, Schoevers et al. 2010). However, in some contexts health gradients show the opposite pattern with higher incidence of suicide, more severe injuries from road accidents and delayed cancer diagnosis in rural parts of some countries (Campbell, Elliott et al. 2001, Levin, Leyland 2005, Weiss, Kaplan et al. 2014).

Of the factors thought to contribute to urban-rural health gradients, social environment may modify the widowhood effect at different stages of bereavement by two different mechanisms. Acute stress during early bereavement may be buffered by intentionally supportive interactions within an individual's social network (or at least the perception that emotional, informational or instrumental support is available - Thoits 2011, Holt-Lunstad, Smith et al. 2010). As time since bereavement increases the 'main-effects' of social relationships may come to the fore; a set of emotional, behavioural or cognitive processes stemming from social relationships that are not intentionally supportive but often have beneficial influences on health (e.g. societal pressure to fulfil a family role may cause people to adopt a healthy lifestyle to fulfil that role Thoits 2011). There is some evidence that social support during widowhood influences health outcomes including mortality risk. A study collating vital event records for over 400,000 elderly couples in the US showed that the race of the partners influences the widowhood effect. Whites in endogamous marriages suffered a large increase in mortality risk but the effect was not evident among blacks, a distinction that may be related to higher levels of familial support for the elderly in black families (Elwert, Christakis 2006).

We investigated the association between the widowhood effect and urban or rural residence, using a large cohort of married couples assembled from the Northern Ireland Mortality Study. In Northern Ireland older people living in rural areas receive more family support, being more likely to live with their children and hence less likely to be admitted to care homes (McCann, Grundy et al. 2014). Adjusting for these differences in family living arrangements, there is an additional reduction in risk of admission to care homes among rural dwellers in comparison with urban dwellers, indicating that greater integration within the wider community may reduce demand for formal care services or replace them when supply is limited (McCann, Grundy et al. 2014). Therefore we predicted that the mortality differential between widows and nonwidows would be less pronounced in rural compared with urban areas, especially once the 
initial period of shock had passed and the availability of longer term instrumental and emotional support had become of greater importance. We investigated these relationships separately for men and women to account for differences in the size of the widowhood effect between sexes (Moon, Kondo et al. 2011).

\section{METHODS}

Data sources

109 The Northern Ireland Mortality Study 2001 (NIMS 2001) is a prospective record-linkage study,

110 derived from the 2001 Census returns for the whole enumerated population (c1.6m), to which

111 subsequent registered deaths to the end of 2009 have been linked. Details of NIMS 2001 and

112 linkage processes are described elsewhere (O'Reilly, Rosato et al. 2012, O'Reilly, Rosato et al.

113 2008). These data were anonymised, held in a safe setting by the Northern Ireland Statistics

114 and Research Agency (NISRA) and made available to the research team for this study. The use

115 of the NIMS 2001 for research was approved by the Office for Research Ethics Committees

116 Northern Ireland (ORECNI).

\section{Definition of cohort}

118 All personal characteristics were drawn from the Census returns which were also used to 119 identify married couples whose members were aged from 26 to 103 at the time of the 2001 120 Census. Couples living in institutional settings (e.g. nursing homes or sheltered 121 accommodation) were excluded. It was not possible to exclude couples who were separated before the death of the first partner. A small number of couples (66) were excluded in which both members died of a common cause within the same calendar month, leaving a total of 296,125 couples. This group experienced 37,821 deaths during the follow-up period (Table 1).

\section{Characteristics of the cohort}

126 In addition to age, sex, religious affiliation and country of birth the following characteristics

127 that have previously been associated with increased mortality risk were extracted from the 128 census records. Five indicators of socio-economic status were included: household car access; 129 educational attainment; social class, derived using the National Statistics Socio-economic 130 Classification (NS-SEC)(Rose, Pevalin 2002); economic activity; and housing tenure 131 (Connolly, O'Reilly et al. 2010)(Table 1). The Census included two indicators of self-reported 132 morbidity - the presence of a long-term illness limiting usual activities; and another on general 133 health in the previous year. The amount of time spent caring for other family members or those 134 with health problems was also recorded, along with the presence of any dependent children 
135 (Ramsay, Grundy et al. 2013, O'Reilly, Connolly et al. 2008). We also sought to adjust for 136 variation in family living arrangements between urban and rural areas (McCann, Grundy et al.

137 2014), recording the presence of other adults in the household who may provide support for 138 the bereaved.

\section{Definition of urban and rural areas}

140 Although there is no universally agreed definition of what constitutes an 'urban' or 'rural' area, 141 the official classification in Northern Ireland (NISRA 2005) uses an approach based on 142 population size, density and access to services to group small population tracts of about 300 143 people into eight settlement bands ranging from the largest, the Metropolitan Area of Belfast 144 (comprising c.580,000 people); to a band representing settlements of less than 1000 people and open countryside. Cohort members were allocated to settlement bands based on place of residence on Census day. Our cohort was unequally distributed among the eight settlement

147 bands (95,714 couples in Belfast compared with 12,307 in villages; Supplementary Materials,

148 Table S1), reducing the power of our analyses to detect temporal trends for the smaller bands

149 and so we re-categorised the bands into three similarly sized groups; urban - comprising the 150 largest two cities; intermediate - combining large, medium, and small towns and intermediate areas, and rural as above.

\section{Analytical methods}

153 The primary outcome measure was all-cause mortality during follow-up on a chronological age 154 timescale. We estimated mortality rates using a Cox proportional hazards model to obtain 155 hazard ratios (HRs) and 95\% confidence intervals (CIs), adjusting for age and all measured 156 characteristics of the household and of the individual (but not of the spouse). Baseline hazards 157 of mortality for men and women are known to be quite different (especially with respect to 158 age) and so separate models were fitted for each sex, rather than a single more complex model with a large number of interaction terms. As a result, between sex comparisons of effect sizes are indirect. A piecewise structure (five time periods) allowed for changes in baseline mortality rates during follow-up as the cohort aged. Recognising that participant characteristics may change during follow-up (e.g. health status improving or declining), we used statistical tests to

163 determine which covariates should be treated as time-varying and which time-invariant. We

164 tested whether there was a significant interaction between each covariate and time period 165 (Likelihood ratio test comparing models with and without a time interaction) using the whole 166 cohort. Covariates selected for subsequent models whose effects were allowed to vary over 
time were: economic activity, car access (males only); household size, housing tenure (females only); caregiving status, long-term limiting illness, general health (both sexes), with the remaining covariates treated as time-invariant.

170 Time since widowhood was included as a time-varying covariate in all models and we conducted two separate analyses, first dividing widowhood into early ( $<6$ months) and later (6 months to 8.7 years) stages. The six month division was selected based on preliminary analysis of the widowhood curve and the approach of previous studies which have identified the first six months as the period of highest risk, associated with shock and acute grief. The effects of changing health behaviours and instrumental support deficits are of greater importance at later stages (Martikainen, Valkonen 1996, Stroebe, Schut et al. 2007, Lusyne, Page et al. 2001, Manor, Eisenbach 2003). To determine whether the effect of each stage of widowhood varied with rurality, we compared models with and without interactions between widowhood duration and rurality (using likelihood ratio tests). The effect of living arrangements (whether couples were living with other adults at baseline) was tested in a similar manner (i.e. testing for interaction between living arrangements and widowhood duration).

In the second analysis widowhood duration was further divided at 1, 3, 6 and 12 months and then annually post-bereavement to determine the trajectory of the widowhood effect. We also conducted a sensitivity analysis to determine whether three-way categorisation of settlement bands masked variability among bands, performing separate analyses for each of the eight bands. All analyses were conducted in Stata version 12 (StataCorp, College Station, Texas).

\section{RESULTS}

188 Summary statistics describing the population at baseline (Table 1) showed that those widowed 189 were older on average than non-widows and hence more likely to have poor health, lower levels 190 of education, be economically inactive and live in smaller households with fewer dependent 191 children. There was no difference between groups or consistent urban/rural gradient in the 192 proportion of couples living with other adults (Table S1).

193 The relative effects of each stage of widowhood varied significantly among areas (likelihood 194 ratio tests for interaction between duration and rurality: men, $P=0.008$; women $P=0.061$ ). 195 Men in urban, intermediate and rural areas had significantly increased hazard of mortality in 196 the first six months of widowhood compared with those that were not widowed (HRs: 1.25 in 197 urban areas, 1.50 in rural and intermediate areas, Table 2). Excess mortality increased again at 
the later stages ( $>6$ months) of widowhood for men in urban areas but not in intermediate or rural areas where the mortality differentials decreased.

200 Among women, the pattern of responses to widowhood across areas in the first six months was similar to that observed among men (i.e. elevated mortality risk in each area but a much smaller increase in urban areas). In all areas the mortality differential between widows and non-widows decreased in the later stages of widowhood. The largest sustained elevation in risk was in intermediate areas followed by urban areas (HRs of 1.22 and 1.09 respectively) with no significant difference remaining in rural areas (Table 2).

206 These effects were reflected in the trajectories of the widowhood effects for each group over time (Figure 1). In rural areas the large initial spike in relative mortality (HRs in the first month 1.71 and 1.67 for men and women respectively) dissipated by the end of the first year of widowhood and a similar trajectory was observed in intermediate areas. Women in urban areas suffered a modest initial increase in mortality (HR of 1.11 during the first month) but there was no sustained elevation in mortality risk after the first year of widowhood (Figure 1). In contrast, men in urban areas showed a greater relative initial increase in mortality risk than women (HR

$213=1.38$ in first month) but the effect persisted and appeared to increase slightly in magnitude 214 during subsequent years. Sensitivity analysis revealed that trajectories of mortality risk were 215 similar across settlement bands within each of the (three-way) urban/rural area classifications 216 although there was considerable uncertainty around risk estimates in bands comprising less 217 than 20,000 couples (not shown - available on request).

218 Mortality risks for couples living with other adults were elevated compared with couples not 219 living with others at baseline (fully adjusted models, all areas combined, HRs and 95\% CIs: men, $1.11[1.08,1.14]$; women, $1.10[1.05,1.14])$. However, living with other adults was not associated with variation in responses to widowhood for either sex in any area (Likelihood ratio tests for interaction between living arrangements and widowhood duration split at six months, all tests $P>0.05$, Table S2).

\section{DISCUSSION}

225 Our estimates of the increase in mortality risk following widowhood are consistent with those 226 found across multiple studies in developed countries (Shor, Roelfs et al. 2012). In intermediate 227 areas, the pattern that we observed of high excess mortality within the early stages of widowhood followed by decreased but still elevated risk in the later stages is very similar to 

1996). However, neither the rapid attenuation of the widowhood effect among the rural

231 bereaved, matching that of non-widows within a year, nor the increasing magnitude of the 232 effect over time among urban dwelling men, have been observed previously. Urban/rural 233 differentials in the widowhood effect remained after adjusting for a wide range of individual 234 predictors that have been associated with variation in mortality risk (e.g. age, social class, 235 health status) but have been frequently overlooked in studies of widowhood (Moon, Kondo et al. 2011). These findings highlight the importance of both individual-level predictors and social context as predictors of health outcomes in Ireland (Tay, Kelleher et al. 2004).

238 In the later stages of widowhood, we found a decreasing trend in magnitude of the widowhood 239 effect from urban to rural areas among men and from intermediate to rural areas among women.

240 These results are consistent with our prediction that the widowhood effect would be less 241 pronounced over the long-term in rural areas in comparison with more densely populated areas 242 and provide support for our hypothesis that the effect is attenuated by greater social integration. 243 However, the urban-rural gradient may also be a proxy for other factors which influence the 244 widowhood effect. For example, residential proximity to green spaces has been associated with 245 less severe declines in general and mental health following stressful life events (van den Berg, 246 Maas et al. 2010) which might eventually manifest as area-specific variation in mortality risk. 247 Furthermore, the effects of proximity to green space on some health outcomes are sex-specific; 248 a UK based study of urban residents found that mortality risk from cardiovascular and 249 respiratory disease decreased with increased access to green space among men but no such 250 association was found among women (Richardson, Mitchell 2010). One explanation for this 251 difference in that proximity to green space encourages regular physical activity among men, 252 but that perceived safety concerns and other social barriers may prevent women from deriving 253 the same health benefits. Similarly, sex-specific differences in the long-term trajectory of the widowhood effect along the urban-rural gradient may be due to differential influence of the residential and occupational environment on levels of physical activity of men and women.

256 Specifically, a recent systematic review (Stahl, Schulz 2014) found limited evidence for an association between bereavement and reduced levels of physical activity (both sports and other leisure activities) among men but not among women. A reduction in physical activity and hence cardiovascular health may partially explain the increased mortality risk for men in urban areas during later stages of widowhood. A similar drop in activity may not have occurred among rural widowers because in these areas manual occupations (particularly farming) are more 
common and so levels of occupational physical activity remain high. In rural parts of Northern Ireland continued engagement in the workforce past normal retirement age is relatively common and may maintain greater social integration among older men than would occur in urban areas (Heenan 2010), potentially contributing to the observed urban-rural differences in the widowhood effect.

267 Urban-rural variation in access to medical care might also have influenced mortality risk among the bereaved; greater distances to primary care services may have discouraged health check attendance of rural residents around the time of bereavement, increasing mortality risk from pre-existing conditions (Shah, Carey et al. 2013). This may explain why the widowhood effect was greater in rural and intermediate than in urban areas during the first six months but it is more difficult to envisage how it might explain the sustained increases in risk among urban but not among rural men. In contrast with the urban-rural differences, presence of other adults was not associated with a decrease in the widowhood effect. This is surprising as during the early stages of bereavement family members are likely to have the most frequent interactions with the bereaved. One hypothesis is that members of the household and the wider community have differing influences on health outcomes of widowed people and that sources of effective social support are situation specific (Thoits 2011). A synthesis of 50 studies of the association between social support and mortality (not at times of bereavement), showed that perceived social support from family members is more beneficial for reducing mortality risk than support from friends (Shor, Roelfs et al. 2013). However, widowhood presents a particular set of emotional challenges and there is evidence that bereaved people find contact with friends promotes emotional well-being and decreases loneliness to a greater extent than contact with family, perhaps because friends freely choose to interact with the bereaved and are less likely to initiate contact out of obligation (Utz, Swenson et al. 2013, de Vries, Utz et al. 2013). This potentially explains why urban/rural variation, which may indicate interaction with the wider community, was associated with the widowhood effect whilst household composition which is likely to indicate contact with family members was not. A similar distinction between household and broader community effects relates to care provision for older people in Northern Ireland; living with children and rural residence were independently associated with lower risk of care home admission among older people (McCann, Grundy et al. 2014). Furthermore, an

292 Australian study found that a high degree of social integration with friends was associated with increased survival among older people but the same relationship was not evident for contact with relatives (Giles, Glonek et al. 2005). Finally, the role of family members in supporting the 
bereaved may have been obscured in our study because living with others may not accurately represent the support available. A recent meta-analysis revealed that structural measures of social relationships including indicators of residential status are more weakly associated with mortality than more complex measures which also incorporate levels of perceived or received support (Holt-Lunstad, Smith et al. 2010).

A limitation to our study was that covariates were only measured at baseline (the 2001 Census) so discrepancies between observed and true values are likely to have increased over time, potentially obscuring associations with the widowhood effect. Self-reported health status is most likely to have changed during follow up, especially amongst older widowed groups, and we attempted to adjust for this by using time-varying effects in our survival models where necessary. This consideration also applies to living arrangements; people may have chosen to move in with others post-bereavement and propensity to move may have varied along the urban/rural gradient. Area of residence may also have changed and in Northern Ireland there has been a net migration from deprived to more affluent areas, typically from cities to the surrounding hinterland, with migrants more likely to be affluent than non-migrants (O'Reilly, Stevenson 2003), and to possess better long term health prospects. The widowhood effect is more pronounced in groups with these characteristics (Shah, Carey et al. 2012) and so selective migration during follow-up could have biased downwards our estimates of the widowhood effect in urban areas. However, migration over large distances is rare $(2.9 \%$ of the population move between postcode sectors annually - O'Reilly, Stevenson 2003) and is less common at

315 the ages where most widowhood occurs. As our urban/rural classification did not require adjustment as a time-varying effect we expect any associated bias to be minor.

317 The Northern Ireland Mortality Study incorporates baseline measurements of marital status and 318 subsequent deaths but not other vital events including divorce and remarriage. Some of the couples in our sample may have been no longer married when the first death occurred, leaving the surviving partner unlikely to suffer the widowhood effect (Elwert, Christakis 2008). The inclusion of this group might bias our estimates of widowhood effect downwards by increasing average mortality rates in the non-widowed group (divorce is also associated with elevated mortality rates - Berntsen, Kravdal 2012, Waite 1995). Any bias is likely to be small because the magnitude of the 'divorce effect' is similar to the widowhood effect (Shor, Roelfs et al. 2012, Rendall, Weden et al. 2011). Also, divorce rates amongst the over 60s (the majority of our sample) are likely to be relatively low, as indicated by age-specific rates in comparable populations in England and Wales (Office of National Statistics 2011). 
328 The modelled variables spanned a wide range of factors likely to influence mortality risk, including measures of self-reported health not usually available for a cohort of this size but it

330 is possible that the observed patterns was driven by variation in an unobserved covariate (e.g. 331 smoking status), a limitation common to many other observational studies of this type.

332 Similarly, urban/rural residence may not accurately reflect received support at the community

333 level (impracticable to measure at large scales, requiring surveys of visits received etc.) and so

334 other interpretations of our results are possible. For example, the observed urban/rural

335 differences may be due to an alternative mechanism, perhaps differences in attitudes to 336 mortality across the urban/rural divide. In Northern Ireland, death is a much larger part of life 337 in rural areas than in cities; news of a death travels fast, attendance at wakes and funerals of 338 even distant acquaintances is expected and these events are important forums for community 339 interaction, aside from providing comfort for the bereaved. As a result, rural funerals tend to 340 be larger than those in urban areas and the considerable stress of mourning in a more prominent 341 setting may contribute towards the larger initial spike in mortality risk that we observed in rural 342 and intermediate compared with in urban areas.

\section{CONCLUSION}

344 In conclusion, we found pronounced urban/rural differences in the effects of widowhood on mortality risk. In urban, rural and intermediate areas we found that in the early stages of widowhood (<6 months) all groups had elevated risks of mortality but the effect was much less pronounced among urban dwellers. In later stages the effect dissipated for rural dwellers and to some extent for intermediate dwellers and urban dwelling women but not for urban dwelling men who remained at a higher risk of mortality than their married counterparts for many years. These effects may be attributable to the positive influence of greater social integration of widowed people into the wider community in rural compared with more densely populated areas. Urban-dwelling men at later stages of widowhood appear to have the greatest need for community support and efforts to increase integration into the wider community might bring considerable benefits for this group. 
357 This study was funded as part of the UK Centre of Excellence for Public Health, Northern

358 Ireland initiative. The funders had no direct role in the conduct of the study; the collection,

359 management, analyses, or interpretation of the data; or the preparation or approval of the

360 manuscript.

361 The help provided by the staff of the Northern Ireland Mortality Study 2001 (NIMS 2001) and

362 the NILS Research Support Unit is acknowledged. The NIMS 2001 is funded by the Health

363 and Social Care Research and Development Division of the Public Health Agency (HSC R\&D

364 Division) and NISRA. The NILS-RSU is funded by the ESRC and the Northern Ireland

365 Government. The authors alone are responsible for the interpretation of the data and any views

366 or opinions presented are solely those of the author and do not necessarily represent those of

367 NISRA/NILS. 


\section{REFERENCES}

371 BERNTSEN, K.N. and KRAVDAL, Ø, 2012. The relationship between mortality and time since divorce, widowhood or remarriage in Norway. Social science \& medicine, 75(12), pp. $3732267-2274$.

BOYLE, P.J., FENG, Z. and RAAB, G.M., 2010. Does Widowhood Increase Mortality Risk?: Testing for Selection Effects by Comparing Causes of Spousal Death. Epidemiology 376 (Cambridge, Mass.), 22, pp. 1-5.

377 CAMPBELL, N.C., ELLIOTT, A.M., SHARP, L., RITCHIE, L.D., CASSIDY, J. and 378 LITTLE, J., 2001. Rural and urban differences in stage at diagnosis of colorectal and lung cancers. British journal of cancer, 84(7), pp. 910-914.

380 CONNOLLY, S., O'REILLY, D. and ROSATO, M., 2010. House value as an indicator of cumulative wealth is strongly related to morbidity and mortality risk in older people: a censusbased cross-sectional and longitudinal study. International journal of epidemiology, 39(2), pp. 383-391.

DE VRIES, B., UTZ, R., CASERTA, M. and LUND, D., 2013. Friend and Family Contact and Support in Early Widowhood. The Journals of Gerontology Series B: Psychological Sciences and Social Sciences, 69B(1), pp. 75 - 84.

387 ELWERT, F. and CHRISTAKIS, N.A., 2008. The Effect of Widowhood on Mortality by the 388 Causes of Death of Both Spouses. American Journal of Public Health, 98(11), pp. 2092-2098.

ELWERT, F. and CHRISTAKIS, N.A., 2006. Widowhood and Race. American Sociological Review, 71(1), pp. 16-41.

391 ELWERT, F. and CHRISTAKIS, N., 2008. Wives and ex-wives: A new test for homogamy bias in the widowhood effect. Demography, 45(4), pp. 851-873.

GILES, L.C., GLONEK, G.F.V., LUSZCZ, M.A. and ANDREWS, G.R., 2005. Effect of social networks on 10 year survival in very old Australians: the Australian longitudinal study of aging. Journal of Epidemiology and Community Health, 59(7), pp. 574-579.

396 HEENAN, D., 2010. Social capital and older people in farming communities. Journal of Aging 397 Studies, 24(1), pp. 40-46.

398 HOLT-LUNSTAD, J., SMITH, T.B. and LAYTON, J.B., 2010. Social Relationships and Mortality Risk: A Meta-analytic Review. PLoS Med, 7(7), pp. e1000316.

400 LEVIN, K.A. and LEYLAND, A.H., 2005. Urban/rural inequalities in suicide in Scotland, 401 1981-1999. Social science \& medicine, 60(12), pp. 2877-2890. 
404 LUSYNE, P., PAGE, H. and LIEVENS, J., 2001. Mortality following conjugal bereavement, 405 Belgium 1991-96: The unexpected effect of education. Population Studies, 55(3), pp. 281-289.

406 MANOR, O. and EISENBACH, Z., 2003. Mortality after spousal loss: are there sociodemographic differences? Social science \& medicine, 56(2), pp. 405-413.

408

409

410

411

412

413

414

415

416

417

418

419

420

421

422

423

424

425

426

427

428

429

430

431

432

433

434

435

436

437

MANZOLI, L., VILLARI, P., M PIRONE, G. and BOCCIA, A., 2007. Marital status and mortality in the elderly: A systematic review and meta-analysis. Social science \& medicine, 64(1), pp. 77-94.

MARTIKAINEN, P. and VALKONEN, T., 1996. Mortality after death of spouse in relation to duration of bereavement in Finland. Journal of epidemiology and community health, 50(3), pp. 264-268.

MARTIKAINEN, P. and VALKONEN, T., 1996. Mortality after the death of a spouse: rates and causes of death in a large Finnish cohort. American Journal of Public Health, 86(8), pp. 1087-1093.

MCCANN, M., GRUNDY, E. and O'REILLY, D., 2014. Urban and rural differences in risk of admission to a care home: A census-based follow-up study. Health and Place, 30, pp. 171-176.

MOON, J.R., KONDO, N., GLYMOUR, M.M. and SUBRAMANIAN, S.V., 2011. Widowhood and mortality: a meta-analysis. PloS one, 6(8), pp. e23465.

NISRA, 2005. Report of the inter-deparmental urban-rural definition group: statistical classification and delineation of settlements. Belfast: Northern Ireland Statistics and Research Agency.

O'REILly, D., ROSATO, M., CATNEY, G., JOHNSTON, F. and BROLLY, M., 2012. Cohort description: The Northern Ireland Longitudinal Study (NILS). International journal of epidemiology, 41(3), pp. 634-641.

O'REILLY, D. and STEVENSON, M., 2003. Selective migration from deprived areas in Northern Ireland and the spatial distribution of inequalities: implications for monitoring health and inequalities in health. Social science \& medicine, 57(8), pp. 1455-1462.

OFFICE OF NATIONAL STATISTICS, 2011-last update, Divorces in England and Wales 2011 [Homepage of Office of National Statistics], [Online]. Available: http://www.ons.gov.uk/ons/rel/vsob1/divorces-in-england-and-wales/2011/index.html.

O'REILLY, G., O' REILLY, D., ROSATO, M. and CONNOLLY, S., 2007. Urban and rural variations in morbidity and mortality in Northern Ireland. BMC Public Health, 7(1), pp. 123.

O'REILLY, D., CONNOLLY, S., ROSATO, M. and PATTERSON, C., 2008. Is caring associated with an increased risk of mortality? A longitudinal study. Social science \& medicine, 67(8), pp. 1282-1290. 
O'REILLY, D., ROSATO, M. and CONNOLLY, S., 2008. Unlinked vital events in censusbased longitudinal studies can bias subsequent analysis. Journal of clinical epidemiology, 61(4), pp. 380-385.

PANDEY, M.K. and JHA, A.K., 2012. Widowhood and health of elderly in India: examining the role of economic factors using structural equation modeling. International Review of Applied Economics, 26(1), pp. 111-124.

PEEN, J., SCHOEVERS, R.A., BEEKMAN, A.T. and DEKKER, J., 2010. The current status of urban-rural differences in psychiatric disorders. Acta Psychiatrica Scandinavica, 121(2), pp. 84-93.

RAMSAY, S., GRUNDY, E. and O'REILLY, D., 2013. The relationship between informal caregiving and mortality: an analysis using the ONS Longitudinal Study of England and Wales. Journal of epidemiology and community health, 67, pp. 655-660.

RENDALL, M.S., WEDEN, M.M., FAVREAULT, M.M. and WALDRON, H., 2011. The Protective Effect of Marriage for Survival: A Review and Update. Demography, 48(2), pp. 481-506.

RICHARDSON, E.A. and MITCHELL, R., 2010. Gender differences in relationships between urban green space and health in the United Kingdom. Social science \& medicine, 71(3), pp. 568-575.

RIVA, M., CURTIS, S. and NORMAN, P., 2011. Residential mobility within England and urban-rural inequalities in mortality. Social science \& medicine, 73(12), pp. 1698-1706.

ROSE, D. and PEVALIN, D., 2002. A Researcher's guide to the national statistics socioeconomic classification. London: Sage.

SHAH, S.M., CAREY, I.M., HARRIS, T., DEWILDE, S., VICTOR, C.R. and COOK, D.G., 2012. Do Good Health and Material Circumstances Protect Older People From the Increased Risk of Death After Bereavement? American Journal of Epidemiology, 176, pp. 689-698.

SHAH, S.M., CAREY, I.M., HARRIS, T., DEWILDE, S., VICTOR, C.R. and COOK, D.G., 2013. Impact of Partner Bereavement on Quality of Cardiovascular Disease Management. Circulation, 128(25), pp. 2745-2753.

SHOR, E., ROELFS, D.J., BUGYI, P. and SCHWARTZ, J.E., 2012. Meta-analysis of marital dissolution and mortality: Reevaluating the intersection of gender and age. Social Science and Medicine, 75(1), pp. 46-59.

SHOR, E., ROELFS, D.J. and YOGEV, T., 2013. The strength of family ties: A meta-analysis and meta-regression of self-reported social support and mortality. Social Networks, 35(4), pp. 626-638.

SHOR, E., ROELFS, D., CURRELI, M., CLEMOW, L., BURG, M. and SCHWARTZ, J., 2012. Widowhood and Mortality: A Meta-Analysis and Meta-Regression. Demography, 49(2), pp. 575-606. 
STAHL, S. and SCHULZ, R., 2014. Changes in Routine Health Behaviors Following Late-life

476 Bereavement: A Systematic Review. Journal of Behavioral Medicine, 37(4), pp. 736-755.

477 STROEBE, M., SCHUT, H. and STROEBE, W., 2007. Health outcomes of bereavement. The 478 Lancet, 370(9603), pp. 1960-1973.

479 TAY, J.B., KELLEHER, C.C., HOPE, A., BARRY, M., GABHAINN, S.N. and SIXSMITH, 480 J., 2004. Influence of sociodemographic and neighbourhood factors on self rated health and 481 quality of life in rural communities: findings from the Agriproject in the Republic of Ireland. 482 Journal of Epidemiology and Community Health, 58(11), pp. 904-911.

483 THOITS, P.A., 2011. Mechanisms Linking Social Ties and Support to Physical and Mental 484 Health. Journal of health and social behavior, 52(2), pp. 145-161.

485 UTZ, R.L., SWENSON, K.L., CASERTA, M., LUND, D. and DEVRIES, B., 2013. Feeling 486 Lonely Versus Being Alone: Loneliness and Social Support Among Recently Bereaved 487 Persons. The Journals of Gerontology Series B: Psychological Sciences and Social Sciences, 488 69B(1), pp. 85- 94.

489 VABLE, A.M., SUBRAMANIAN, S.V., RIST, P.M. and GLYMOUR, M.M., 2015. Does the 490 "widowhood effect" precede spousal bereavement? Results from a Nationally Representative 491 Sample of Older Adults. The American Journal of Geriatric Psychiatry, 23(3), pp. 283-292.

492 VAN DEN BERG, A.E., MAAS, J., VERHEIJ, R.A. and GROENEWEGEN, P.P., 2010. 493 Green space as a buffer between stressful life events and health. Social science \& medicine, 494 70(8), pp. 1203-1210.

495 WAITE, L.J., 1995. Does Marriage Matter? Demography, 32(4), pp. 483-507.

496 WEISS, H.B., KAPLAN, S. and PRATO, C.G., 2014. Analysis of factors associated with 497 injury severity in crashes involving young New Zealand drivers. Accident Analysis \& 498 Prevention, 65(0), pp. 142-155.

499 
Table 1. Baseline characteristics of married couples in Northern Ireland, 2001, by widowhood (2001-2009) and sex.

\begin{tabular}{|c|c|c|c|c|}
\hline & Males & Widowers & Females & Widows \\
\hline Cohort (no.) & 283,685 & 12,440 & 270,744 & 25,381 \\
\hline Deaths & 25,447 & 2,658 & 12,506 & 2,962 \\
\hline Person years at risk & $2,428,777$ & $44,961.25$ & $2,428,777$ & $101,339.5$ \\
\hline Annual mortality risk (\%) & 1.05 & 5.91 & 0.51 & 2.92 \\
\hline Age - mean (SD) & $49.9(13.7)$ & $66.4(12.1)$ & $46.9(12.8)$ & $64.7(11.3)$ \\
\hline \multicolumn{5}{|l|}{ Economic activity a } \\
\hline Employed & 49.28 & 17.97 & 50.63 & 17.22 \\
\hline Self employed & 18.13 & 8.20 & 4.63 & 1.98 \\
\hline Unemployed & 2.90 & 1.75 & 1.48 & 0.54 \\
\hline Inactive & 24.59 & 44.05 & 41.08 & 60.46 \\
\hline Aged 75+ & 5.10 & 28.03 & 2.19 & 19.80 \\
\hline \multicolumn{5}{|l|}{ Social class (NS-SEC) ${ }^{a}$} \\
\hline Professional & 32.06 & 19.08 & 28.81 & 15.63 \\
\hline Intermediate & 6.09 & 4.24 & 17.13 & 11.15 \\
\hline Small employers/self employed & 18.44 & 11.47 & 4.93 & 3.59 \\
\hline Lower supervisory & 7.20 & 6.22 & 4.53 & 3.72 \\
\hline (Semi) routine & 28.50 & 28.20 & 37.60 & 38.20 \\
\hline Never worked/Long term & 2.62 & 2.74 & 4.82 & 7.92 \\
\hline unemployed/full-time student & & & & \\
\hline \multicolumn{5}{|l|}{ Education $^{\text {a }}$} \\
\hline No qualifications & 47.02 & 53.49 & 40.14 & 58.61 \\
\hline Foundation level & 14.11 & 4.16 & 17.86 & 6.03 \\
\hline GCSEs & 10.83 & 5.05 & 17.45 & 8.15 \\
\hline 2+ A-Levels & 4.94 & 1.58 & 6.71 & 1.94 \\
\hline First degree & 11.77 & 5.21 & 11.36 & 4.22 \\
\hline Higher degree & 6.24 & 2.48 & 4.29 & 1.25 \\
\hline \multicolumn{5}{|l|}{ Car access } \\
\hline None & 6.76 & 18.22 & 6.05 & 19.93 \\
\hline One & 43.59 & 56.06 & 43.16 & 54.29 \\
\hline wo + & 49.65 & 25.72 & 50.79 & 25.78 \\
\hline \multicolumn{5}{|l|}{ Housing tenure } \\
\hline Owner occupied & 87.39 & 76.67 & 87.76 & 78.16 \\
\hline Privately rented & 4.02 & 4.49 & 3.98 & 4.73 \\
\hline Social rented & 8.59 & 18.83 & 8.26 & 17.11 \\
\hline \multicolumn{5}{|l|}{ Long term limiting illness } \\
\hline Yes & 23.73 & 44.34 & 21.56 & 43.34 \\
\hline No & 76.27 & 55.66 & 78.44 & 56.66 \\
\hline \multicolumn{5}{|l|}{ General health } \\
\hline Good & 64.78 & 42.67 & 63.11 & 39.44 \\
\hline Fair & 22.72 & 36.46 & 23.99 & 37.69 \\
\hline Not good & 12.50 & 20.87 & 12.9 & 22.88 \\
\hline \multicolumn{5}{|l|}{ Unpaid carer } \\
\hline None & 84.93 & 73.1 & 79.33 & 72.41 \\
\hline 1-19 hours & 9.60 & 7.72 & 12.63 & 7.96 \\
\hline 20-49 hours & 1.93 & 4.08 & 3.12 & 4.05 \\
\hline $50+$ hours & 3.54 & 15.10 & 4.93 & 15.57 \\
\hline \multicolumn{5}{|l|}{ Dependent children } \\
\hline None & 48.77 & 87.45 & 46.82 & 88.53 \\
\hline One & 16.59 & 6.42 & 17.11 & 6.01 \\
\hline
\end{tabular}




\begin{tabular}{|c|c|c|c|c|}
\hline Two & 20.16 & 3.73 & 20.99 & 3.24 \\
\hline Three+ & 14.48 & 2.40 & 15.08 & 2.23 \\
\hline \multicolumn{5}{|l|}{ Other adults in household } \\
\hline No & 71.73 & 70.92 & 71.81 & 70.52 \\
\hline Yes & 28.27 & 29.08 & 28.19 & 29.48 \\
\hline \multicolumn{5}{|l|}{ Country of birth } \\
\hline Northern Ireland & 89.96 & 89.72 & 89.55 & 90.01 \\
\hline England & 4.45 & 3.96 & 3.87 & 2.90 \\
\hline Scotland & 1.24 & 1.58 & 1.13 & 1.11 \\
\hline Wales & 0.26 & 0.27 & 0.17 & 0.20 \\
\hline Republic of Ireland & 2.38 & 3.55 & 3.45 & 4.63 \\
\hline Ireland (place not specified) & 0.16 & 0.13 & 0.14 & 0.12 \\
\hline Other & 1.55 & 0.79 & 1.69 & 1.02 \\
\hline \multicolumn{5}{|l|}{ Religion (community background) } \\
\hline Roman Catholic & 36.87 & 32.43 & 38.61 & 32.08 \\
\hline Presbyterian & 26.66 & 28.84 & 25.90 & 30.07 \\
\hline Church of Ireland & 18.46 & 21.91 & 18.44 & 21.66 \\
\hline Methodist & 4.53 & 5.14 & 4.57 & 5.44 \\
\hline Other Christian & 10.88 & 9.98 & 10.41 & 9.40 \\
\hline Other/none & 2.61 & 1.70 & 2.07 & 1.35 \\
\hline \multicolumn{5}{|l|}{ Rurality } \\
\hline Urban & 36.4 & 43.4 & 36.2 & 41.7 \\
\hline Intermediate & 33.6 & 32.2 & 33.8 & 31.7 \\
\hline Rural & 30.0 & 24.4 & 30.0 & 26.6 \\
\hline
\end{tabular}

501 Abbreviation: SD, standard deviation.

502 Percentage of cases in each cohort at baseline given for categorical variables.

$503{ }^{a}$ Economic activity, social class and education variables have the same percentage of cases

504 with participants aged 75+. Percentages listed for economic activity only. 
Table 2. Effect of widowhood on hazard of mortality by rurality and temporal stage of widowhood, Northern Ireland, 2001-2009.

\begin{tabular}{lllll}
\hline \multicolumn{2}{c}{ Men } & \multicolumn{3}{c}{ Women } \\
\hline Rurality & $<6$ months & $\geq 6$ months & $<6$ months & $\geq 6$ months \\
Urban & $1.25(1.07,1.47)$ & $1.35(1.26,1.44)$ & $1.24(1.06,1.46)$ & $1.09(1.01,1.17)$ \\
Intermediate & $1.50(1.25,1.80)$ & $1.22(1.13,1.33)$ & $1.57(1.31,1.87)$ & $1.22(1.12,1.33)$ \\
Rural & $1.50(1.22,1.85)$ & $1.09(0.99,1.21)$ & $1.49(1.21,1.84)$ & $1.06(0.96,1.17)$ \\
\hline
\end{tabular}

507

508 HRs and 95\% CIs given for each group (compared with the non-widowed). Separate models

509 fitted for each sex and rurality classification, adjusted for age, economic activity, social class,

510 education, household size and car access, housing tenure, health status (general health and

511 limiting long-term illness), presence of others in household (both dependent children and non-

512 dependents), country of birth and religion. 


\section{FIGURES}

515 Figure 1. Effect of time since bereavement (HR and 95\% CIs) on hazard of mortality for

516 widowed people compared with those not widowed, Northern Ireland, 2001-2009. Separate

517 models fitted for each sex and rurality classification, adjusted for age, economic activity, social

518 class, education, household size and car access, housing tenure, health status (general health

519 and limiting long-term illness), presence of others in household (both dependent children and

520 other adults), country of birth and religion. First eight years of bereavement shown. Log scale.
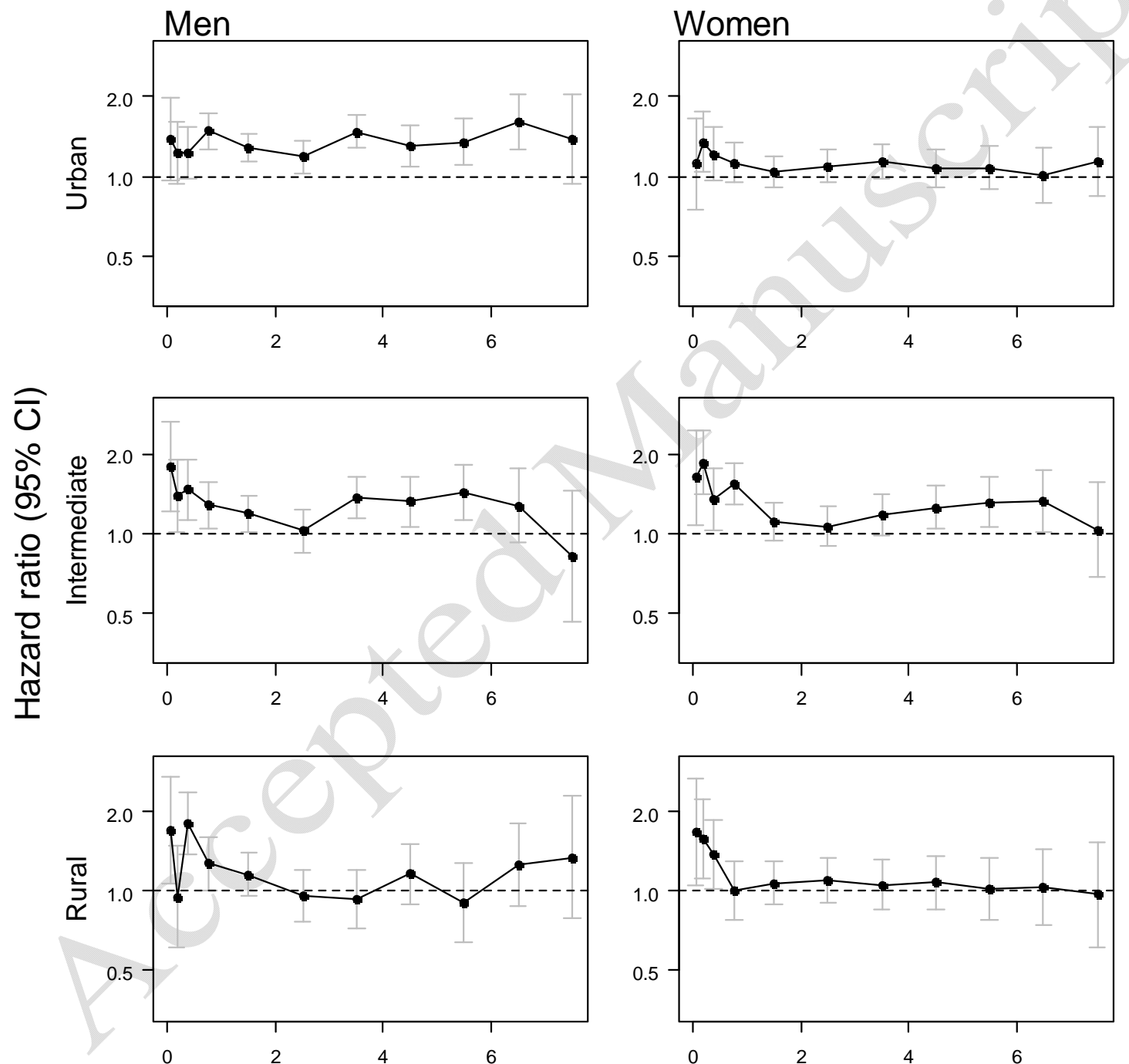

Years post bereavement 
Table S1. Proportion of couples living with other adults by settlement band, Northern Ireland, 2001.

Couples Living with other adults (\%)

\section{Settlement band}

$\begin{array}{lcc}\text { A - Belfast } & 95714 & 26.23 \\ \text { B - Derry } & 12909 & 33.91 \\ \text { C - Large towns } & 39100 & 26.69 \\ \text { D - Medium towns } & 16943 & 27.35 \\ \text { E - Small towns } & 18602 & 24.27 \\ \text { F - Intermediate settlements } & 12458 & 25.00 \\ \text { G - Villages } & 12307 & 26.53 \\ \text { H - Rural } & 88092 & 32.20\end{array}$


Table S2. Effect of living with others adults on hazard of mortality by rurality, Northern Ireland, 2001-2009.

\begin{tabular}{lllll}
\hline \multicolumn{2}{c}{ Men } & \multicolumn{2}{c}{ Women } \\
\hline Rurality & HR & LRT interaction & HR & LRT interaction \\
& & $P$ & $1.10(1.03,1.17)$ & 0.464 \\
Urban & $1.10(1.05,1.15)$ & 0.216 & $1.16(1.08,1.24)$ & 0.654 \\
Intermediate & $1.12(1.06,1.18)$ & 0.821 & $1.08(1.00,1.17)$ & 0.117 \\
Rural & $1.11(1.05,1.17)$ & 0.880 & & \\
\hline
\end{tabular}

527

528 HRs and 95\% CIs given for each group (compared with those living with a spouse only).

529 Separate models fitted for each sex and rurality classification, adjusted for age, economic

530 activity, social class, education, household size and car access, housing tenure, health status

531 (general health and limiting long-term illness), presence of dependent children, country of birth

532 and religion. Likelihood ratio tests compared models in which the effect of living with others

533 was allowed to vary with stage of widowhood ( $<6$ months, $\geq 6$ months) with models in which

534 there was no such interaction. 